\title{
Bio-based biodegradable hydrogels prepared by crosslinking of microbial poly $(\gamma$-glutamic acid) with L-lysine in aqueous solution
}

Saeko Murakami, Nobuyoshi Aoki and Shuichi Matsumura

Polymer Journal (2011) 43, 809; doi:10.1038/pj.2011.68

Correction to: Polymer Journal (2011) 43, 414-420; published online 19 January 2011; doi:10.1038/pj.2010.142

In the above article, unit given for $x$ axis variables for Figure 8 line graph was wrong. It should have been cultivation time in number of days, as shown below.

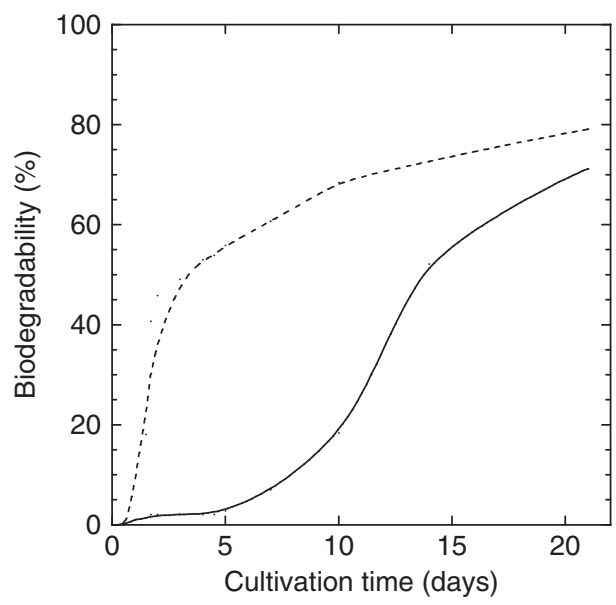

Figure 8 Biochemical oxygen demand-biodegradation test of the poly $(\gamma-$ glutamic acid) (PGA) gel (solid line) and aniline (dashed line) using activated sludge at $25^{\circ} \mathrm{C}$. The PGA gel was prepared with $50 \mathrm{mg}$ of PGA dissolved in $0.35 \mathrm{ml}$ of $1.0-\mathrm{M} \mathrm{NaOH}, 17.7 \mathrm{mg}$ of L-lysine. $\mathrm{HCl}$ dissolved in $0.08 \mathrm{ml}$ of water and $1.0-\mathrm{M} \mathrm{NaOH}$ to adjust the $\mathrm{pH}$ to 8.9 , and $54 \mathrm{mg}$ of 4 (4,6-dimethoxy-1,3,5-triazin-2-yl)-4-methylmorpholinium chloride dissolved in $0.20 \mathrm{ml}$ of water at $25^{\circ} \mathrm{C}$ for $24 \mathrm{~h}$. 